\title{
EL VIAJE AL OTRO MUNDO DE UN MALLORQUIN
}

El viaje al Más Allá, al trasmundo, sin necesidad de morir y poder regresar para contarlo ha sido una aventura que parecía reservada tan sólo a los héroes o a los semidioses. Desde hace miles de años, y no exagero porque el Gilgamesh sumerio es del tercer milenio a. de C., los escritores se han complacido en relatar el viaje al Otro Mundo. Fue, y es, una manera de escapar de la realidad con la que el escritor plasmaba el deseo de todos los hombres. Fruto de su imaginación, de auténticas visiones o de sueños, o acumulación de motivos de otras literaturas.

Todos los pueblos tienen sus leyendas en las que las fuentes se mezclan y reelaboran constantemente para narrar el viaje del héroe al Otro Mundo. Para llegar allá sólo le basta atravesar un largo túnel, o una selva oscura, pasar el río con una barca o cruzar un puente más sutil que un cabello y más afilado que una espada. Para unos el Más Allá es el mundo de los muertos, otros lo localizan en el hades o el infierno cristiano, puede estar también en el Paraíso Terrenal, jardín, edén o en el interior de una montaña; para otros es la ciudad celestial o el reino submarino, las entrañas de la tierra o, quizá, esté en la luna. Habitado por muertos, por pigmeos o por hadas; en unos textos es lugar de atroces suplicios y angustias y en otros de felicidad eterna.

La motivación del viaje puede ser la búsqueda de un ser querido - simplemente la curiosidad; aunque a veces el protagonista no sabrá nunca porqué ha sido atraído hacia lugares a donde no pensaba ir.

Toda esta variedad supone el gran atractivo que tenía para los escritores y para los lectores la idea de la existencia de otro mundo, diferente al nuestro; un mundo, Otro, desconocido. 
Algunos escritores franceses allá por la segunda mitad del siglo XII incorporaron en sus novelas algunos motivos que procedian de la mitología greco-latina o de las leyendas célticas que armonizaron con otros del inagotable fondo del folklore universal y con su fabulación personal otorgaron un nuevo estilo al viaje al Otro Mundo ya que de acuerdo con la intencionalidad de la novela cortés, el viaje al Más Allá se convirtió en una aventura caballeresca.

Chrétien de Troyes, María de Francia y otros escritores de los que algunos no sabemos su nombre, como los autores de las Continuaciones del Cuento del Grial o los de los lais anónimos o los de las novelas artúricas en verso o en prosa, imprimieron al viaje al Otro Mundo una serie de caracteristicas o signos fácilmente identificables para los lectores y que constituyeron un particular motivo literario.

En estas novelas que entran dentro de la denominación de Materia de Bretaña, el Otro Mundo está estrechamente vinculado al de los mortales y la aventura que supone llegar a él sirve para poner en relación estos dos mundos: uno real, enmarcado claramente en el de la sociedad cortés de los siglos XII y XIII, y otro vagamente insinuado, el del Más Allá, donde el tiempo no existe, donde la primavera es eterna y donde el héroe, el caballero que llega hasta allí se encuentra siempre con una aventura "maravillosa". En estos relatos ambientados en una Bretaña vagamente localizada que se balancea entre la toponimia real y la fantástica, vemos que aparecen con frecuencia estos signos que antes aludiamos y que otorgan al relato una especifica estructura narrativa. Los espacios, los gestos, los colores y algunos animales pierden sus caracteristicas propias y se convierten en representaciones, en imágenes del Más Allá.

Comentaré ahora algunos de estos motivos que aparecen por primera vez en muchas de las novelas francesas de finales del siglo XII y que continuaron repitiéndose hasta encontrarlos en la novela catalana de la segunda mitad del siglo XIV, La Faula, del escritor mallorquín Guillem de Torroella, que los recoge y al mismo tiempo les otorga unas características nuevas y originales.

En las novelas francesas en laśque aparece el tema del Más Allá el protagonista es, siempre, un caballero, un noble cuya única ocupación es la de medir su fuerza y su valor en justas y torneos, formar parte del séquito del rey, frecuentar la corte y conversar con las damas. Un día, que suele coincidir con uno de estos días privilegiados que aparecen señalados con otro color en los calendarios: Pentecostés, la noche de San Juan, la llegada de la primavera... sale este caballero a pasear o a cazar 
y entra en un bosque tras las huellas de un animal, ciervo, jabali o perro, con frecuencia de color blanco, el color de los encantamientos y de la magia, el color ausente de color que dentro de la simbología sugiere la alteridad de este Otro Mundo. El animal que atrae al caballero, al mortal, es el cebo que le conducirá hasta el Otro Mundo: es un animalguía que una vez que cumpla su misión desaparecerá o se metamorfoseará en un ser sobrenatural.

Para llegar al Otro Mundo, el caballero debe de atravesar una "frontera húmeda", río, lago, fuente o mar que separa pero que también es puerta de acceso al Otro Mundo. Agua-espejo que permite pasar al Otro Lado y que va estrechamente unida a la aparición del elemento maravilloso, a lo sobrenatural.

Porque una de las aventuras "maravillosas" que puede ocurrirle a nuestro héroe en este Otro Mundo de eterna primavera, suaves colinas, fuentes puras e inagotables, frutas deliciosas y pajaros cantores es su encuentro con una mujer bellísima, sola o acompañada de otras de iguales caracteristicas que habitan en este Otro Mundo. Esta mujer tiene un ambigüo atractivo pues goza de unos encantos físicos reales: corporeidad, belleza, generosidad que demuestra dando al caballero unos regalos que están de acuerdo con el mundo cortés al que pertenece: ricos vestidos, oro, plata, veloces caballos, servidores. Pero también es poseedora de unos rasgos excepcionales y sobrenaturales: quien ella elija no podrá jamás amar a otra, no envejecerá nunca, vivirá siempre; y sus dones tienen mágicas propiedades: un anillo que le preservará de la muerte o que le haga invisible, un silbato que paralizará a las fieras. A cambio de todo ello el caballero, que se ha enamorado profundamente de esta mujer, cuando regrese a su mundo, al mundo de los mortales, no podrá revelar este encuentro; si lo hiciera desaparecerían los regalos, los años pasados en el Otro Mundo se pondrían de manifiesto pues envejecería en un segundo y sus familiares y amigos ya no existirían; $y$, sobre todo, nunca más volvería a verla a ella, a la Mujer - Hada.

La narrativa de la Materia de Bretaña, sobre todo la artúrica y la leyenda tristaniana se conocieron pronto en la Corona de Aragón, quizá antes que en otros reinos de la Península Ibérica. Desde finales del siglo XII encontramos en trovadores catalanes alusiones a temas y a personajes de estas narraciones. Se conocieron primero en francés o quizá en versiones en lengua de oc que no poseemos y luego pasaron a traducirse al catalán. El reinado de Pedro el Ceremonioso, largo reinado de 1336 hasta 1387, supuso un importante periodo para las letras catalanas. 
Los inventarios de su biblioteca, personal y patrimonial, y los documentos de su reinado nos dan cuenta no sólo de los libros que poseía el rey sino de los que hizo traducir al catalán, de los que prestaba o pedía prestados para que le fueran copiados y un sinfin de aspectos intimos relacionados con los libros que nos demuestran claramente que Pedro el Ceremonioso no fue tan sólo un rey bibliófilo, un coleccionista de libros, sino que fue un rey lector. Traducciones al catalán del Lancelot en prosa, del 'Tristán, la Queste del Sainta Graal; están inventariados el libro de la Taula Redonda, el "liber regis Meliadux" escrito en francés; padres e hijos de la Casa Real se prestaban el Roman de la Rose y el Roman de Renart. De las paredes de sus palacios colgaban tapices que representaban escenas artúricas y la onomástica de la época se enriquece con los nombres de personajes novelescos: Tristany, Galvany, Isolda, etc.

Pero que las obras literarias francesas eran ampliamente conocidas y aceptadas en la Corona de Aragón, se demuestra cuando aparecen las primeras obras de producción propia. El ambiente, los personajes, los temas, las aventuras tan características, e incluso la forma primitiva de los primeros romans, los versos pareados que en Cataluña se llamaron noves rimades, fueron adoptados por escritores catalanes; de algunos sabemos sus nombres, otros son anónimos. No son muchas las muestras de esta literatura en la segunda mitad del siglo XIV pero la variedad de temas, caballerescos, poemas corteses, alegóricos, satíricos, algún fablaux, ponen en evidencia el gran atractivo que tenía esta literatura para el escritor y para los lectores.

Aquí voy a referirme únicamente a La Faula texto de clara influencia francesa pero con unos aspectos nuevos y originales.

El autor, Guillems ay nom de Torroella (v. 818), mientras paseaba a caballo la mañaña de San Juan por el puerto de Sóller (Mallorca) vio en la playa una ballena tan inmóvil que parecía una roca, a la que acompañaba un papagayo. Guillem se subió encima de la ballena y el peixó emprendió una rápida carrera. A media noche la singular nave llegó a tierra firme y Guillem "desembarcó". En la copa de un árbol repleto de frutas deliciosas estaba una serpiente que llevaba en la frente un carbunclo que iluminaba el paisaje. Guillem vio que estaba en un prado cubierto de flores junto a una fuente de mármol llena de agua clarísima. La serpiente hablándole en francés le dijo que estaba en la Isla Encantada en donde vivían el rey Arturo y su hermana el hada Morgana. Guillem se durmió allí mismo y se despertó con la luz del amanecer. Paseando por aquel lugar del que describe la belleza del pai- 
saje y mientras pensaba, asombrado, en la aventura (v. 214) que le habia sucedido, se acercó a él un palafrén con ricos arreos en el cual estaban insertados en oro, plata y marfil unos dibujos que representaban escenas de los romans franceses más importantes. Cuando el caballo emprendió la marcha unos cascabeles hacían sonar un lays de Tristán (v. 286). Guillem montó y el palafrén le llevó por un camino a través de un prado; Guillem cogió unos guantes con adornos de oro y plata que colgaban de un laurel y se unieron a su paseo dos perritos blancos muy juguetones y más adelante un gavilán de bellas plumas que estaba devorando una codorniz.

El palafrén se detuvo al divisar un palacio y Guillem decabalgó. Se acercó a él una joven bellísima doncella que hablándole en francés le dio la bienvenida y le dijo que estaba ante una aventura ... aysi beylla, Si estrange ni si novella (vv. 498-499) que no le habia ocurrido a ningún otro hombre.

- Dadme noticias del rey Arturo, le dijo Guillem. La joven se dio a conocer como el hada Morgana, hermana del rey, - El rey está en el palacio, le dijo, enfermo de una extraña enfermedad que le ha quitado la alegria.

Guillem y Morgana entraron en el palacio que estaba adornado con mucho lujo y cuyas vidrieras representaban las hazañas, los amores y las diversiones de los personajes más importantes de la narrativa artúrica francesa. Guillem se extrañó de no ver al rey; entonces Morgana le pasó por delante de los ojos un anillo con un zafiro incrustado que tenía el poder de convertir en luz la oscuridad y de esta manera Guillem vio claramente al rey. Detras de unas rejas de plata estaba Arturo de Bretaña sentado en un rico lecho y su apariencia era como la de un caballero de unos treinta años. Estrechaba en sus manos una espada a la que miraba fijamente mientras lloraba. A sus pies dos mujeres vestidas de negro mostraban una actitud afligida. El hada Morgana le explicó a Guillem que las damas eran las dos hermanas del rey, Amor y Valor, antes reinas y ahora huérfanas y viudas que acudian al rey para ser socorridas.

Entonces el rey Arturo se puso a hablar con su espada, Escalibor, lamentándose de que los actos nobles y valerosos y el amor verdadero no eran estimados y la caballería había desviado su verdadera naturaleza; a causa de ello deseaba morir.

Las damas empezaron a llorar muy fuerte y el gavilán que Guillem aún llevaba en el puño hizo sonar sus cascabeles y esto hizo que el rey viera a Guillem y le preguntara quién era y de dónde venía. Tomó 
la palabra Morgana para explicar que cuando el rey recuperó su espada Escalibor se puso muy contento pero enseguida se entristeció, y por ello habia enviado a buscar a Guillem a Mallorca por medio de una fantasma enxantea (v. 876) con aspecto de ballena para que pudiera explicar de regreso lo que había visto y oído en la Isla Encantada y la causa de la tristeza del rey.

Guillem lleno de extrañeza le preguntó al rey:

-Ets vós, Sényer, lo rey Artús, Aycell qui atendon li bretó? (vv. 922-923) y a continuación le relata todo lo que sabe acerca de los últimos momentos del rey: la batalla de Salesbières en la que el rey fue ferits mortalmén (v.947), la espada lanzada al lago por Girflet, la nave del hada Morgana que recogió al rey y cómo unos dias después se encontró la tumba del rey. Y como Guillem sabia que el relato de la muerte del rey estaba escrito dudaba de que aquel caballero que tenia delante fuera el rey Arturo. El rey le contestó: -Ge suy Artús, qui mante Payne E mant travayl pasey mant jor Por exaucer prets e valor; (vv. 990-992), le explica que la nave de Morgana le condujo hasta la isla en donde están. Morgana le curó de las heridas al bañarle en una fuente de grant vertu (vv.1032) cuya agua procedia del rio Tigris. Mientras, Morgana hizo construir la tumba para que sus súbditos no se expusieran a grandes peligros al intentar encontrarle creyendo que aún estaba vivo.

Guillem seguía extrañado por el juvenil aspecto del rey a pesar de su avanzada edad, y el rey le explica que una vez al año le visita el Santo Grial que le nutre con el maná y esto es lo que le otorga el aspecto sano y joven. Y el motivo de su tristeza lo sabrá Guillem si mira atentamente en su espada y el rey se la entrega a través de las rejas de plata. Guillem vio en la espada dos grupos de personas, unas tristes que tenian los pies atados y las otras alegres pero con los ojos vendados. E] rey le explica que las que tienen los ojos tapados son los hombres ricos pero viles y están contentos porque son ricos a causa de su avaricia; y los que tienen los pies atados estiman el valor pero no tienen ánimo para hacer lo que quisieran, por eso suspiran. El rey encargó a Guillem que cuando regresara explicara bien todo lo que habia visto.

Guillem montó en el palafrén y junto con el gavilán, los perritos y guiado por el papagayo llegó a la playa en donde le estaba esperando la ballena. Montó en el pez y navegando toda la noche, Guillem llegó a la mañana siguiente al puerto de Santa Caterina en donde encontró su caballo en el mismo lugar en donde lo había dejado el día anterior. Montó en él y se dirigió vas Mallorques (v.1236) dando gracias a Dios. 
La Faula es un interesante documento sobre la evolución de las leyendas artúricas y su divulgación en tierras catalanas de las que su autor se muestra gran conocedor y que sigue muy fielmente cuando resume los acontecimientos más importantes en torno al final del rey Arturo. En la Historia regum Britanniae, dice Godffroy de Monmouth que el rey Arturo, al final de sus dias, fue llevado a la isla de Avalón ad sananda vulnera sua, para curar de sus heridas. En la Vita Merlini este mismo autor nos da una imagen de la insula pomorum que fortunata vocatur, tomando aspecto de San Isidoro y otros relativos a las Islas Afortunadas y diciéndonos que allá fue el rey Arturo en busca de salud. Parece ser que insula pomorum es la traducción de Avalón, que en celta quiere decir "isla de las manzanas". Y en muchas leyendas célticas aparecen los viajes y expediciones de Arturo a lugares fantásticos asociados con el Otro Mundo.

La Historia regum Britanniae fue traducida y ampliada por el escritor anglonormando Wace en el Roman de Brut y de esta manera la historia de Arturo de Bretaña fue conocida por un público culto y sirvió de fuente para otros escritores como Chrétien de Troyes, María de Francia y los anónimos autores de la Vulgata en prosa.

La Faula cuando explica por boca de Morgana, del rey Arturo y del propio Guillem los últimos momentos del rey en la batalla de Salesbières sigue fielmente el texto en prosa francesa de la primera mitad del siglo XIII, La Mort Artu, pero se aleja de esta ortodoxa tradición cuando localiza en Sicilia el lugar en donde se reponía el rey de sus heridas. Efectivamente, la Isla Encantada es Sicilia. No sólo lo demuestra la distancia señalada vagamente por el autor, pues en dirección a oriente navega a lomos de la ballena desde por la mañana hasta el anochecer, que es poco más o menos la distancia de 500 millas que separa ambas islas, sino que La Faula sigue con una tradición que unía la cálida isla mediterránea a las leyendas artúricas. Gervasio de Tílbury en los Otia imperalia (c.1212) cuenta que un servidor del obispo de Catania persiguiendo un caballo que se había desbocado por una ladera del Etna se encontró en una gran llanura en donde se levantaba un palacio suntuoso en el que vivía el rey Arturo. Allí había sido transportado el rey después de la batalla de Salesbières y cada año se le volvian a abrir las heridas. En el Florian et Florete, novela francesa de la segunda mitad del XIII, el rey Arturo residia en Sicilia con su hermana Morgana. Y en el Jaufré, relato en provenzal escrito entre finales del siglo XIl y principios del XIII, esta fada del Gibel que se lleva 
al héroe al cap del mon e ben desutz terra preon (vv. 10654 y 10475 10476) parece que se refiere a Morgana y a su residencia en lo más profundo del Etna. Por su enclave a medio camino entre oriente y occidente, conquistada por los normandos en 1070 y lugar de embarque de cruzados, esta isla mediterránea no fue ajena a las tradiciones y leyendas del norte de Europa.

El aire fantasmal que ya desde Monmouth adquiere el final del rey Arturo, que recoge dubitativamente Wace y que se intensifica en la Mort Artu, llena por completo el ambiente de La Faula. La Faula no es una novela cortés, un roman courtois, no hay héroe que realice hazañas caballerescas por amor a su dama ni que viaje en busca del amor de la Mujer-Hada. La Faula es el viaje al Más Allá de Guillem de Torroella a la Isla Encantada, atraido por el Hada Morgana para regresar a su mundo con un mensaje de intención moralizadora y crítica social. Viaje, sin embargo, lleno de aspectos mágicos y misteriosos y con una escenografia espectacular.

Guillem de Torroella en su breve relato de 1269 versos que empieza en la mañana de San Juna, fiesta llena de prodigios desde el folklore más antiguo, presenta una auténtica acumulación de recursos procedentes de la materia de Bretaña expuestos de manera detallista, minuciosa y ornamental. De una geografia coherente y real: Mallorca, Sóller y el puerto de Santa Caterina, pasamos al de la Isla Encantada, quizá Sicilia, pero presentada de manera ambigüa y cargada de propiedades maravillosas, pues es refugio del hada y del rey inmortal. Guillem viaja acompañado siempre por toda una serie de animales-guía, mensajeros del hada: la ballena, el papagayo, la serpiente habladora, el caballo de suntuoso arnés y los perritos blancos que le conducen, le ayudan, le facilitan el encuentro sobrenatural. Entre estos animales y el protagonista hay una relación telepática pues son conscientes de formar parte de una empresa común en la que los destinos del hombre y el de estos animales se funden y caminan al unísono.

Y por otro lado aparece en La Faula en un movimiento pendular, con ingenuo realismo, la plasmación de aspectos cotidianos de la vida que también hemos observado en Chrétien de Troyes. El miedo de Guillem cuando navega a lomos de la ballena que le impulsa a proferir la oración de los agonizantes (vv.62-71), los guantes De la talla de Perpinyà (v.347), las alusiones a las novelas y a los personajes más importantes de la narrativa francesa, su manera de presentarse ante el rey: Pres les rexes m'ajenoley, (C'axí deu hom parlar ab rev) Perquè'l vulch far real honor. (...) Guillems ay nom de Torroella, Mos payres era cavallers, Mas 
eu soy enquer escuders, Car no hay l'orde recebut. (vv. 805-807; 818-821), el gavilán siempre en el puño, etc.

La impresionante entrevista con el rey Arturo tiene un significado moralizador y alegórico acerca del poder y la fortuna y la decadencia de los valores caballerescos y la esperanza de una posible restauración de éstos. Mensaje críptico y algo vago que se enraíza en los textos de filósofos y de moralistas y con la literatura didáctica y de visiones. Si la escenografia de La Faula debió de entusiasmar a los lectores contemporáneos de Guillem de Torroella, y sigue interesándonos a todos los que nos ocupamos de la literatura medieval, hay otros aspectos que no debemos pasar por alto pues señalan una nueva perspectiva en la tradición de los relatos artúricos.

La Faula es un relato autobiográfico, es decir que la voz y el punto de vista del narrador se identifican con el del protagonista: Guillems ay nom de Torroella (v. 818) que nos dice que Un'aventura'us vull retrayre Qui'm avench enquer no ha gayre. Si com porets ausir anan. (vv. 1-3). Autobiografia fingida y puramente imaginaria pero que confiere al relato un carácter de realidad.

El concepto de realidad y de realismo, y por consecuencia el concepto del "yo" individual que tienen el autor y el lector de la Edad Media son radicalmente diferentes de los conceptos de realidad y de "yo" individual en que se apoya la teoría poética de la narración en primera persona que propone la crítica para los textos modernos. El "yo" narrativo del escritor medieval es ante todo un "yo" poético, la figura retórica de un "yo" ficticio que representa, según palabras de Leo Spitzer, al alma humana. De acuerdo con ésto los datos de carácter singular y biográfico que se creen poder atribuirsele no tienen otro objeto que dar cuerpo a la experiencia individual, entendida como pura experiencia ontológica y no como acontecimiento personal e intransferible.

Realidad de carácter arquetípico y poblado de arquetipos ejemplares, más intuída o revelada que experimentada, más propia del mundo religioso de los mitos y de los milagros que del mundo físico y circunstancial del hombre de carne y hueso. Esto quizá pueda explicar porqué entre las más significativas narraciones en primera persona que nos ha llegado la literatura medieval, el viaje al Otro Mundo, las visiones o los sueños extraordinarios ocupan un lugar preeminente.

El "yo" autobiográfico satisfacia la sensibilidad del lector medieval, ayudaba a la credibilidad de la acción, o a buena parte de ella, y el narrador-protagonista servia de pretexto literario para la exposición 
gráfica de una ideología y por la que la experiencia individual se mostraba como dimensión histórica, incluso en la adopción de la lengua vernácula como el vehículo más adecuado para la expresión del nuevo concepto de realidad.

El mensaje del rey Arturo de Bretaña que avisa de la decadencia de los valores caballerescos y da los remedios que pueden aplicarse, puede ser considerado como otro sermón moralista más propio de los siglos XIV y XV, o también como un discurso monárquico con una intención política concreta inscrita, tambien, en la época de Guillem de Torroella. Y este mensaje ha de ser divulgado por el propio Guillem de Torroella por orden expresa del mismo rey. El escudero mallorquin no ha sido absorto espectador de una aventura maravillosa en el Más Allá, ha sido protagonista activo, elegido, que puede y debe contar lo que le ha sucedido en la Isla Encantada. Ha roto con la prohibición de relatar lo que sucedia en el Otro Mundo. Mensajero de su propia aventura, Guillem de Torroella regresa a Mallorca, para contar La Faula, para escribir su faula. Y La Faula no le abandonará ni a él ni a sus descendientes porque en documentos e inventarios procedentes del Archivo de la Corona de Aragón aparecen en diferentes épocas nombres de miembros de la familia Torroella designados con el apelativo "de la faula".

La repercusión literaria de La Faula tomó varias direcciones: su huella es visible en el Libre de Fortuna e Prudència de Bernat Metge y también en Lo somni, en algunos escritores de Turmeda y en otros escritores catalanes de finales del siglo XIV y del XV. Pero es en el Tirant lo Blanc cuando encontramos una influencia evidente, directa e incluso a veces literal en los capítulos 189 al 212. Durante un banquete en las suntuosas fiestas que se celebran en el palacio imperial de Constantinopla aparecen unas doncellas vestidas de negro que se llaman Honor, Castidad, Esperanza y Belleza que anuncian la llegada al puerto de Morgana que va en busca de su hermano. El rey Arturo estaba en Constantinopla dentro de una jaula con rejas de plata mirando fijamente su espada Escalibor. Cuando salió de la jaula todos se alegraron mucho y se pusieron a bailar, Tirant con Morgana y el rey Arturo con Carmesina, y después celebraron una abundante cena en la nave. En estos capítulos el mítico y lejano rey Arturo y su misteriosa hermana, el hada Morgana, se mezclan con naturalidad con personajes de características tan reales 
como todos los que aparecen en el Tirant; y esto es debido a que el episodio artúrico dento de la novela catalana es un entremés que se representó en la corte de Constantinopla, es decir, una pequeña representación teatral que sirve para que Martorell sin romper el constante realismo y verosimilitud del Tirant introduzca los personajes y el ambiente mítico de mayor fortuna literaria de la literatura francesa medieval.

ISABEL DE RIQUER (Universidad de Barcelona) 


\section{BIBLIOGRAFIA}

BADIA LOLA: De la Faula al Tirant lo Blanc, passant, sobretot, pel LLibre de Fortuna e Prudència, "Quaderns Creme, deu anys", Barcelona, 1989, págs. 17-57.

BUTINYÀ I JIMENEZ, JÚliA: Una nova font del Tirant lo Blanc, "Filología Románica", 7: 1990, Editorial Universidad Complutense, Madrid, 1990, págs.

ESPADALER, ANTON: El meravellós com a luxe i pedagogia, "El món imaginari i el món meravellós a l'edat mitjana". Fundació Caixa de Pensions, Barcelona, 1986, págs. 137-149.

HARF-LANCNER, LAURENCE: Les fées au Moyen Age. Morgane et Mélusine. La naissance des fées, Paris, Champion, 1984.

LOOMIS, R.S., The Legend of Arthur's survival, en Arthurian Literature of the Middle Ages, Oxford, Oxford University Press, 1959.

PACHECO, ARSENI: Le narració en primera persona en els segles XIV i XV: notes per a una reavaluació crítica, "Actes del Cinqué Colloqui d'Estudis Catalans a Nord-Amèrican" a cura de P. Rasico i C. Wittlin, Barcelona, North American Catalan Society, Abadia de Montserrat, 1988. Patch, Howard Rollin, El otro mundo en la literatura medieval, México, Fondo de Cultura Económica, 1956.

RIQUER, ISABEL DE: La literatura francesa en la Corona de Aragón en el Reinado de Pedro el Ceremonioso, 1336-1387, en "Imágenes de Francia en las letras hispánicas", Barcelona, P.P.U., 1989, págs. 115-126.

RIQUER, MARTIN DE: Història de la Literatura Catalana, II; Barcelona, Ariel, 1964, págs. 26-41.

TORROella, GUILlEM DE: La Faula, edició de Pere Bohigas i Jaume Vidal-Alcover, Tarragona, Edicions Tarraco, 1984. 